\title{
EL DIESTRO JUEGO POÉTICO DE ROBERT FROST EN 'UNA PAUSA EN EL BOSQUE EN UN ANOCHECER NEVADO"
}

\author{
María de los Ángeles Castro Hidalgo
}

\begin{abstract}
RESUMEN
J. R. Kreuzer y Lee Cogan en el libro Literature for Composition señalan dos de los criterios preferidos por los críticos de poesía para caracterizar este género literario. Unos destacan ante todo su fuerza sintetizante; otros, la calidad de su juego metafórico. Sin embargo, tanto Kreuzer como Cogan creen que ambos aspectos son igualmente vitales en la poesía. El poeta norteamericano Robert Frost (1874-1963) así lo demuestra en "Una pausa en el bosque en un anochecer nevado". Su genialidad se hace evidente en este caso gracias al excelente juego metafórico logrado en un espacio relativamente corto: cuatro estrofas con cuatro líneas cortas cada una.
\end{abstract}

\begin{abstract}
James R. Kreuzer and Lee Cogan in their book Literature for Composition point out two of the most important characteristics of poetry, according to a good many critics of this genre. For some, it is compression; for others, a good and well-worked metaphor. Meanwhile, Kreuzer and Cogan end up thinking that both criteria can be equally relevant. To illustrate their point of view "Stopping by the Woods on a Snowy Evening" by Robert Frost (18741964 ) is analyzed. Frost's artistic achievement is evident not only from Kreuzer and Cogan's point of view but also from that of Aristotle, a man for whom to be a master of metaphor was indeed "a sign of genius" (Aristotle cited by Richter 1975: 105).
\end{abstract}

Cuando los críticos hablan de la esencia de la poesía, nos comentan James R. Kreuzer y Lee Cogan (1965: 250), dos criterios parecen disputarse el primer lugar. Unos críticos destacan ante todo su fuerza sintetizante: la transmisión del mensaje y de la emoción deseados utilizando el menor número de palabras. Otros por su parte, se inclinan a favor de la calidad del juego metafórico dentro del poema. En este caso el mensaje y la emoción deseados surgen por medio de los valores que el poeta logra imprimirle a la imagen (Kreuzer y Cogan 1965: 250). El buen manejo de la imagen tiene inclusive su razón científica de ser si se toma en cuenta la forma en que el conocimiento humano se transmite. John Frederick Nims, por ejemplo, nos recuerda que: "aproximadamente $3 / 4$ partes del área de nuestro cerebro procesa información que se capta a través de los sentidos de la vista, el oído, el olfato" (1983: 4). Sin embargo, tanto Kreuzer como Cogan consideran que ambos criterios pueden ser igualmente tomados en cuenta como aspectos indiscutiblemente vitales en la poesía; en realidad, la síntesis y la metáfora no son excluyentes la una de la otra $(1965: 250)$. 
Robert Frost (1874-1963), conocido como el poeta norteamericano de Nueva Inglaterra de atracción universal (Bradley, Beatty, Long (eds.) 1967: 1063), confirma que, ciertamente, un buen poeta puede, en espacios relativamente cortos, afianzarse confiadamente en la imagen para de ahí pasar primero a la metáfora y luego al símbolo, lo abstracto ('lejano' en latín), lo opuesto a lo concreto (Kreuzer y Cogan 1965: 250). En el caso particular del poema corto "Una pausa en el bosque en un anochecer nevado", la descripción física de un área en pleno invierno conduce al lector a pensar en el mundo interior del yo lírico: la metáfora. Ésta, a su vez, le cede el paso al símbolo, a saber, la fuerza seductora de la muerte para un ser humano que, como en este caso, se encuentra marcado severamente por el agotamiento o el debilitamiento de su energía vital en un momento dado. Este fluir secuencial rápido y certero de la imagen hacia el símbolo, confirma la calidad poética de Frost tanto desde la óptica de Kreuzer y Cogan como desde la óptica misma de Aristóteles, para quien una metáfora bien lograda es signo claro de ingenio (Aristóteles citado por Richter 1975: 105).

En este poema de cuatro estrofas relativamente cortas cada una, el yo lírico aparece ubicado frente a un paraje con árboles que se cubren de nieve cada vez más. Su blancura contrasta con el incremento de oscuridad de la noche que avanza; un escenario alejado del mundanal ruido, lleno de suaves silencios y de quietud:

De quién es este bosque -creo saberlo

Pero él vive allá en la villa

Y no verá que me detengo

A contemplarlo mientras lo cubre la nieve.

Mi pequeño caballo debe pensar que es raro

Detenerse aquí sin que casa alguna esté cerca

En medio de un bosque y de un lago congelado

Justamente en el más oscuro anochecer del año.

Él mueve sus juegos de campanillas

Para preguntar si es que ha habido algún error.

El otro sonido que escucho es solamente el del suave

Soplar del viento y el tenue caer de la nieve.

El bosque es bello, oscuro y profundo

Sin embargo tengo aún promesas que cumplir

$\mathrm{Y}$ tengo millas que recorrer antes de dormir

$\mathrm{Y}$ tengo millas que recorrer antes de dormir.

(Frost citado por Bradley, Beatty, Long (eds) 1967: 1083-84)

En la primera estrofa el yo lírico nos describe un entorno que le resulta familiar y atractivo; la descripción suscita un sentimiento de lejanía de cualquier contexto humano, de quietud. El bosque poco a poco se cubre de nieve cuyo color blanco evoca la imagen misma del efecto de la muerte cuando ésta se posesiona de la existencia humana:

De quién es este bosque - creo saberlo

Pero él vive allá en la villa

Y no verá que me detengo aquí

A contemplarlo mientras lo cubre la nieve. 
El deseo del yo lírico por pasar inadvertido es evidente; el dueño está lejos, no lo verá dentro de sus tierras. Igualmente evidente es su deseo de detenerse junto a esa imagen y de contemplarla. Pero esta primera intención de contemplación estética ampliará su significado más adelante. La atracción que él siente hacia ese mundo exterior hará referencia a su realidad interna: a la drástica reducción de su propia energía vital.

La segunda estrofa suscita la sensación óptica de oscuridad y de paralización de vida. Estos aspectos a su vez hacen que la pausa adquiera un matiz extraño. A falta de vida y a falta de luz la contemplación parece carecer de lógica. Aún el caballo muestra su desconcierto ante la decisión de su jinete; no hay rastro de casa alguna cerca, que en el marco de referencia dado sería sinónimo de vida. Evidentemente, el animal está bien entrenado para reconocer el peligro: la amenaza de muerte del paraje circundante:

\footnotetext{
Mi pequeño caballo debe pensar que es raro

Detenerse aquí sin que ninguna casa esté cerca

En medio de un bosque y de un lago congelado

Justamente en el más oscuro anochecer del año.

(est. 2)
}

Todo hace pensar que hay otra razón más que la meramente contemplativa originando la pausa. La oscuridad que avanza, la nieve, el frío invernal, el inhóspito ambiente circundante parecen ofrecer suficientes razones para que un ser lleno de vida busque alejarse rápidamente de ese escenario que se torna cada vez menos preciso, y por ende, más peligroso.

La tercera estrofa continúa marcando contrastes entre vida y muerte apelando básicamente al sentido del oído. La decisión del hombre ha perturbado al caballo, un ser inferior pero que muestra capacidad en ese momento de discriminar bien entre seguridad y peligro, entre vida y muerte. Por eso, "Él mueve sus juegos de campanillas / Para preguntar si es que ha habido algún error" (11.1-2, est. 3). La contrastante respuesta de ambos seres ante el mismo hecho, la pausa, se enfatiza. El ser lírico refleja su deleite o su alto grado de identificación con su entorno a través de la imagen que sus palabras configuran, "El otro sonido que escucho es solamente el del suave / Soplar del viento y del tenue caer de la nieve" (11. 3-4, est. 3).

El narrador no sólo contempla sino que se deja seducir por los elementos propios de la escena: la oscuridad, el frío, el silencio, el rostro blanco de ese mundo. Hábilmente el poeta ha deslizado al lector por la ruta que él planeó. Así le da la oportunidad de captar por medio de sus respuestas vivenciales, sensoriales, el significado metafórico de la imagen, específicamente la de ese bosque en donde logra ubicarlo. El yo lírico parece haber encontrado algo que ansiaba; la rima entre ambos mundos, el externo y el suyo propio, parece ser perfecta. La metáfora se abre exitosamente a los ojos del lector.

En la cuarta estrofa el narrador lírico nos recuerda aquello que pareció ser inicialmente su intención al detenerse frente al bosque, la de captar la belleza estética de ese espacio, "El bosque es bello, oscuro y profundo" (1.1, est.4). Sin embargo, es precisamente en esta línea en donde se vislumbra el tercer nivel que la imagen ha de alcanzar. El área no solo le resulta agradable desde un ángulo estético. También le luce increíblemente atractiva por una razón que hace explícita: el bosque es oscuro y profundo, aspectos que en vez de generar en él el deseo de huir le producen una fascinante seducción. Esas dos características son las que, en contraste, alejarían a un ser cargado de fuerza vital de ese contexto. 
El narrador lírico ha de continuar su marcha pero lo hará por compromisos que aún debe cumplir. Reconoce que, muy a su pesar, la hora de cerrar sus ojos y de dejarse llevar por la oscura noche como en suave y añorado sueño aún se halla distante:

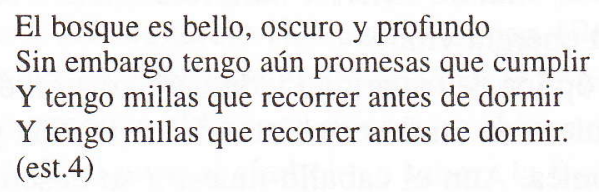

Así es como, en esta cuarta y última estrofa, se opera el cambio semántico de la palabra bosque por el de muerte sin el cual el poema sería básicamente un poema descriptivo. No obstante, la metáfora ha logrado forjarse con ayuda de ese elemento particular llamado imagen, concretamente la de ese bosque que poco a poco se cubre de nieve, de silencios y de oscuridad. El lector logra reconocer en ella aspectos que concuerdan con el debilitado estado anímico interior del hablante quien abiertamente muestra una fuerte, cautivadora atracción por ese entorno oscuro, frío, profundo, silencioso, distante.

La posible ecuación simbólica bosque =muerte ha emanado con la ayuda, primero de la imagen y luego de la metáfora. El bosque se convierte en sinónimo de muerte, en ese caso añorada, con efectos relajantes, placenteros para un viajero bastante cansado, pero quien aún se halla en una ruta cuyo final está distante. Y tan cierto resulta ser este cambio semántico que ambas palabras podrían intercambiarse: "La muerte es bella, oscura, y profunda". De esta forma la connotación del término muerte se hace aún más evidente: alejamiento de este mundo bañado por el sol, su luz, su calor, la vida que genera.

Es en el fluir de esta serie de niveles que radica en gran medida el éxito del poema. Sin mayor tardanza el lector logra adentrarse en la idea por medio del vehículo universal de la imagen. El llegar a la idea de muerte añorada implica a su vez movimiento como nos afirma Barbara Richter en Children of the Fire. Y ella agrega: "En la metáfora encontramos un significado concentrado, y en la metáfora, el significado se desplaza" (1975: 105). Para Richter la metáfora en su acepción general viene a ser toda "una serie, o continuum, de estructuras: la imagen, la metáfora, el símbolo, el mito" que pueden entrelazarse en ese orden "en un accionar cualitativo" (1975: 106). Así entonces, la metáfora es también un término particular dentro de esa definición general, un término tan específico como lo son hipérbole, símil o personificación, por ejemplo (Richter 1975: 106).

En el caso del poema aquí analizado, el yo lírico, y más concretamente su mundo interior, logra sentirse a gusto, embelesado, diríase que reflejado, en ese bosque invernal, nevado, oscuro, solitario. Una vez consolidada esta metáfora, el poema invita al lector a descifrar el símbolo, un concepto de muerte determinado: aquel que desde la óptica de un agotado viajero, adquiere características de quietud y de relajamiento al igual que un ansiado y tranquilo sueño, "bello, oscuro y profundo."

$\mathrm{Y}$ es que todo este juego metafórico tiene su razón de ser. "El sentimiento fortalece el pensamiento", recalca nuevamente Richter en su estudio sobre el tema; "la percepción concretiza el concepto" (1975: 106). Y ese fluir del pensamiento a través de una imagen claramente delineada fue una característica constante en el quehacer poético de Frost. Él fue explícito al respecto: "I'm always saying something that's just the edge of something more" 
("Siempre estoy diciendo algo que sugiere algo más") (Bradley, Beatty, Long (eds) 1967: 1063). La imagen del bosque invita al lector a dirigirse hacia la idea de muerte, cosa que Frost logra a través de esa serie de niveles secuenciales ya apuntados.

Robert Frost ilustra así el pensamiento de Kreuzer y Cogan sobre poesía basado en los dos criterios más importantes señalados, según ellos, por varios críticos de este género: a saber, la calidad del juego metafórico y la fuerza sintetizante que acompaña al poema. Desde esa óptica, Robert Frost cumple éxitosamente su cometido poético en el caso de "Una pausa en el bosque en un anochecer nevado", gracias a su evidente destreza en manejar la metáfora en un espacio relativamente corto: cuatro estrofas con cuatro breves líneas cada una. Y cabe aquí señalar que la metáfora que es bien lograda siempre es digna de un gozoso aplauso pues no sólo le da frescura al lenguaje y a la experiencia que concreta, más aún, de acuerdo con Aristóteles una buena metáfora, "implica una percepción intuitiva de semejanza en aquello que aparentemente es diferente" (Aristóteles citado por Richter 1975: 105). Y justamente para Aristóteles esa destreza, intransferible por naturaleza, resulta ser la "señal de ingenio" (Aristóteles citado por Richter 1975: 105).

\section{Notas}

1. Los textos fueron consultados en inglés. La traducción del poema y de las citas del material secundario las hizo libremente la autora del artículo.

\section{Bibliografía}

Bradley et al (eds.). 1967. The American Tradition in Literature. New York: Grosset and Dunlap Inc.

1967. "Robert Frost”. En: Bradley, Sculley, Beatty Richmond Cross, Long E. Hudson (eds.), 1063-1098.

Kreuzer, James and Lee Cogan. 1965. Literature for Composition. New York: Holt, Rinehart, and Winston, Inc.

1985. "Robert Frost” En: Mc Michael, George (ed), 1513.

Mc Michael, George (ed). 1985. Concise Anthology of American Literature. New York: Mac Millan Publishing Company.

Nims. J. F. 1983. Western Wind: An Introduction to Poetry. New York: Random House Inc.

Richter, Barbara. 1975. Children of the Fire. San José: Editorial Texto. 